\title{
Performance of standardized tasks and evidence-based surgery may increase the chance of success in breast conserving treatment
}

\author{
Gianluca Franceschini \\ Division of Breast Surgery, Department of Women's and Children's Health, Fondazione Policlinico Universitario Agostino Gemelli IRCCS, \\ Università Cattolica del Sacro Cuore, Rome, Italy \\ Correspondence to: Gianluca Franceschini. Division of Breast Surgery, Department of Women's and Children's Health, Fondazione Policlinico \\ Universitario Agostino Gemelli IRCCS, Università Cattolica del Sacro Cuore, Largo A. Gemelli, 8 - 00168, Rome, Italy. \\ Email: gianlucafranceschini70@gmail.com. \\ Provenance and Peer Review: This article was a free submission to the editorial office, Gland Surgery. The article did not undergo external peer review. \\ Response to: Lesniak DM, Clough KB, Killelea BK. Revisiting the modern toolkit to optimize breast conservation surgery. Gland Surg 2020;9:478-80.
}

Submitted May 24, 2020. Accepted for publication Jul 10, 2020.

doi: 10.21037 /gs-20-523

View this article at: http://dx.doi.org/10.21037/gs-20-523

I read with interest the Editorial Commentary of David M. Lesniak and colleagues (1) and would like to emphasize some useful information in order to decrease the rate of reoperations after lumpectomy.

I agree that the oncoplastic breast-conserving surgery (OBCS) "represents an important addition to improve the quality of care for breast cancer patients" and "it is mandatory that breast surgeons incorporate all tools available to reduce the number of reoperations after lumpectomy" (1).

I think that evidence-based breast surgery is the better tool to optimize outcomes in breast conserving surgery (BCS) by integrating best research evidence, clinical and surgical expertise (experience and skills tailored to a particular patient) and woman values (patient attitudes and preference towards disease and its management) in a shared decision-making.

When a BCS is performed, updated scientific knowledge and surgical experience adapted to patient-specific values are essential requirements in order to increase the chance of success.

As regards the scientific knowledge, various studies have shown that OBCS is a reproducible, safe, and effective alternative to conventional techniques (2-4); it allows to obtain the resection of more breast tissue with safer margins, optimal oncological and aesthetic outcomes, lower re-excision rates and good health-related quality of life; OBCS represents an excellent tool to achieve adequate margins and decrease the risk of local recurrence and revision surgery for positive margins $(5,6)$. All breast cancer patients identified as likely to require breast surgery should be considered for oncoplastic procedure, as they may potentially benefit from it. The indications for every oncoplastic technique are different, and various algorithms have been developed to facilitate the decision process (7-9). The choice is usually based on tumor characteristics (location and size), breast characteristics (shape, size and glandular density), the extent of resection, previous surgery and the wishes and expectations of the patient.

As regards patient values, every woman should be informed about main advantages and issues of oncoplastic procedures in order to make a conscious choice; a personalized multidisciplinary pathway should provide an adequate psychological support, an accurate clinical counselling, appropriate information about OBCS and margins guidelines ("no ink on tumor" as the new margin standard after breast conserving surgery for invasive carcinoma); each patient should be managed by the best research evidence as a benchmark, but also with a surgical treatment tailored to her specific features, individual wishes and personal preferences.

As regards surgical experience, OBCS involves a series of more demanding and complex techniques that require additional learning, appropriate surgical practice and 
dexterity; in decision-making process about OBCS it is always necessary to consider some issues related to these procedures (9): longer operative times; surgical morbidity with increased risk of complications such as skin flap and nipple-areola complex ischemia; possible sequelae with negative impact on health-related quality of life.

However, surgical dexterity in oncoplastic surgery is important but not sufficient to optimize the results; a successful OBCS requires both individual capacity and technical ability, but also other qualities as decisionmaking skills, dedication and the repetitive performance of standardized tasks. So, when performing BCS, it is always necessary to put attention to some precise and essential steps in order to minimize the risk of failure, such as (10):

* Careful radiological preoperative assessment with ultrasonography, mammography and selective use of magnetic resonance in order to evaluate the extent of disease and localize tumor and/or calcifications;

- Weekly multidisciplinary discussion, in a dedicated "Surgery Meeting" in order to choose the better oncoplastic procedure tailored to patient;

- Use of intraoperative ultrasound in order to guide the initial resection in a more precise way;

- A meticulous dissection by electrocautery preserving an adequate subcutaneous thickness in order to maintain the vascular viability and minimize the risk of skin and nipple-areola necrosis;

- Intraoperative X-rays and pathological evaluation of the specimen for the definition of the tumor and the margins of resection; frozen sections should be obtained from a portion of every face of the excised specimen in order to assess margins in an optimal way;

* Routine circumferential cavity shaving in order to have a backup to lumpectomy margins and increase negative margin rates;

* Systematic palpation and ultrasound of all glandular tissue at the end of the surgical procedure in order to exclude the presence of further macroscopic tumor foci;

* Placement of clips within the excision cavity as a 'landmark' in order to define the tumor bed and guide adjuvant breast radiotherapy after surgical treatment;

* Accurate pathological management and assessment of the specimen using histological large sections (macrosections).

Adequate training, acquisition of appropriate technical skills and repetitive practice of a multidisciplinary pathway allow to optimize oncological and aesthetic outcomes, obtain more easily tumor-free margins and reduce the number of reoperations after lumpectomy.

I think that the application of the evidence-based surgery together with the repetitive performance of specific standardized tasks could improve breast surgeon's ability and increase the chances of success when he faces the challenges of the most demanding oncoplastic procedures.

\section{Acknowledgments}

Funding: None.

\section{Footnote}

Conflicts of Interest: The author has completed the ICMJE uniform disclosure form (available at http://dx.doi. org/10.21037/gs-20-523). GF has no conflicts of interest to declare.

Ethical Statement: The author is accountable for all aspects of the work in ensuring that questions related to the accuracy or integrity of any part of the work are appropriately investigated and resolved.

Open Access Statement: This is an Open Access article distributed in accordance with the Creative Commons Attribution-NonCommercial-NoDerivs 4.0 International License (CC BY-NC-ND 4.0), which permits the noncommercial replication and distribution of the article with the strict proviso that no changes or edits are made and the original work is properly cited (including links to both the formal publication through the relevant DOI and the license). See: https://creativecommons.org/licenses/by-nc-nd/4.0/.

\section{References}

1. Lesniak DM, Clough KB, Killelea BK. Revisiting the Modern Toolkit to Optimize Breast Conservation Surgery. Gland Surg 2020;9:478-80.

2. Weber WP, Soysal SD, El-Tamer M, et al. First international consensus conference on standardization of oncoplastic breast conserving surgery. Breast Cancer Res Treat 2017;165:139-49.

3. Clough KB, van la Parra RFD, Thygesen HH, et al. Longterm Results After Oncoplastic Surgery for Breast Cancer: A 10-year Follow-up. Ann Surg 2018;268:165-71. 
4. Masetti R, Di Leone A, Franceschini G, et al. Oncoplastic techniques in the conservative surgical treatment of breast cancer: an overview. Breast J 2006;12:S174-80.

5. Landercasper J, Bennie B, Ahmad HF, et al. Opportunities to reduce reoperations and to improve interfacility profiling after initial breast-conserving surgery for cancer. A report from the NCDB. Eur J Surg Oncol 2019;45:2026-36.

6. Benjamin MA, Sinnott C, Bawa S, et al. Re-excision Rate after Partial Mastectomy in Oncoplastic Breast-Conserving Surgery: A Single-Institutional Experience and Review of the Literature. Ann Plast Surg 2019;82:S170-2.

7. Clough KB, Kaufman GJ, Nos C, et al. Improving breast cancer surgery: a classification and quadrant per

Cite this article as: Franceschini G. Performance of standardized tasks and evidence-based surgery may increase the chance of success in breast conserving treatment. Gland Surg 2020;9(4):1069-1071. doi: 10.21037/gs-20-523 quadrant atlas for oncoplastic surgery. Ann Surg Oncol 2010;17:1375-91.

8. Chatterjee A, Gass J, Patel K, et al. A Consensus Definition and Classification System of Oncoplastic Surgery Developed by the American Society of Breast Surgeons. Ann Surg Oncol 2019;26:3436 44.

9. Mitchell SD. A step-by-step oncoplastic breast conservation surgical atlas of reproducible dissection techniques and anatomically ideal incision placement. Breast Cancer Res Treat 2017;165:505-16.

10. Franceschini G, Masetti R. Oncoplastic Breast-Conserving Surgery: Is Technical Skill All That Is Needed? Ann Plast Surg 2020;84:471. 